\title{
The Relationship Between Physical Activity and Quality of Life During the COVID-19 Pandemic: A Case of Female and Male Physical Education Teachers
}

\author{
Berna ÖZCAN ${ }^{1}$ (D) Leyla SARAÇ ${ }^{*}$ (iD) \\ ${ }^{1}$ Department of Physical Education and Sports, Faculty of Sports Sciences, Mersin University, Mersin, Turkey
}

Keywords

COVID-19,

Physical activity,

Physical education,

Teacher,

Quality of life,

\section{Article History}

Received 14 August 2021

Revised 18 December 2021

Accepted 23 December 2021

Available Online 30 December 2021

\footnotetext{
* Corresponding Author:

Leyla SARAÇ

E-mail Address:

1sarac@mersin.edu.tr
}

\begin{abstract}
The aim of this study was to examine the relationship between the physical education teachers' leisure-time physical activity levels during the COVID-19 pandemic and the impact level of the COVID-19 pandemic on their quality of life. A total of 155 physical education teachers, with an average age of 42.39 , participated in the research. To collect data, the Leisure-Time Physical Activity Questionnaire and the COVID-19 Impact on Quality of Life Scale were used in the study. The results obtained in the research showed that the mean score of COVID19 impact on teachers' quality of life is 3.30 (minimum 1; maximum 5). This score on the scale showed that the COVID-19 pandemic negatively affected the quality of life of teachers, above the average. The research findings showed that there was statistically no significant difference between the leisure-time physical activity levels of male and female physical education teachers and the level of impact of COVID-19 on teachers' quality of life. It was also found that there was a negative significant relationship between teachers' leisure-time physical activity level during the COVID-19 pandemic and the impact level of COVID19 on the teachers' quality of life and that as the teachers' leisure-time physical activity level increases, the negative impact of COVID-19 on their quality of life decreases. As a result, in this study, the associated role of physical activity in reducing the effects of factors that negatively affect the quality of life of individuals, including the COVID-19 pandemic, was revealed.
\end{abstract}




\section{INTRODUCTION}

Spread the world from the city of Wuhan, China, which is the biggest and the most crowded country of continent Asia, and defined as a severe acute respiratory syndrome with symptoms like dry cough and temperature, Coronavirus was named as "COVID-19" by World Health Organization (WHO), considering the infection speed of the disease to the world, the COVID-19 was identified as a global pandemic (WHO, 2020). With this pandemic reaching a level that could affect the world in a short time, countries had to take measures that involved all areas of life to prevent the infection speed of the disease (Kalayc1 et al., 2021). With these measures taken, people were aimed to interact with each other to the minimum, daily life activities and traveling were restricted, areas serving daily movement needs of people (gyms, fitness halls, stadiums, swimming pools, parks, etc.) were shut down, and additionally, lockdowns were applied all around the world (Theis et al., 2021). Social distance and movement restrictions aimed at the COVID-19 pandemic created a deeply damaging effect on the whole world by transforming the way individuals are physically active into a new form (Alfawaz et al., 2021), and that is why many individuals became unable to join regular individual or group physical activities outside their houses (Bas et al., 2020). Several studies conducted in this term put forward many proofs for the decrease in physical activity levels of individuals in process of lockdowns related to the COVID-19 pandemic (Caputo \& Reichert, 2020; López-Valenciano et al., 2020; Puccinelli et al., 2021; Stockwell et al., 2021; Tison et al., 2020). In one of these studies, analyzing 48 studies presenting physical activity levels in the COVID-19 pandemic process, Caputo and Reichert (2020) reported that the measures taken related to keeping social distance led to the decrease of physical activity levels of individuals. In another study, 66 scientific studies stating the changes in physical activity levels before and during the COVID-19 pandemic were analyzed, and it was identified that the physical activity level of individuals from all ages and health groups decreased compared to before the pandemic (Stockwell et al., 2021). In a study in the U.S.A, it was presented that the measures put into action to decrease the infection number and protect the public health-related to the COVID-19 decreased the physical activity level of individuals who were physically active before by 32.3\% (Meyer et al., 2020).

Defined as any kind of body movement by consuming energy using muscles and joints, physical activity, besides bringing many benefits like preventing non-infectious diseases such as cancer and diabetes, and like decreasing depression and anxiety symptoms, continues to be among the privileged topics to be popularized all around the world because of its positive 
effect on healthy growth and development of children and young people (Ministry of National Health, 2014; WHO, 2021; Y1ldırım et al., 2008). More specifically, the relationship between physical activity and quality of life, which is defined as the living standard that the individual perceives through his/her life expectancies and aims in the scope of the culture and values $\mathrm{s} /$ he is in, was presented with the previous studies, and it was seen in these studies that the quality of life level increases as physical activity level increases (Anokye et al., 2012; Gill et al., 2013; Pucci et al., 2012; Vagetti et al., 2014). In a study analyzing the studies between 1980-2010 about the physical activity and quality of life relationships in adult individuals, it was reported that there is a positive relationship between physical activity and quality of life and that there is an increase in quality of life with the increase of physical activity (Pucci et al., 2012). Studying 55 pieces of research in a systematic review study, Bize et al. (2007) also concluded that there is a positive relationship between physical activity in the general adult population and quality of life level. In a recent study reviewing the studies conducted between 2006-2018, Marquez et al. (2020) reached the finding that physical activity supports the quality of life positively, especially in individuals aged 18-65 and older. The findings obtained as a result of studying the relationship between physical activity level and quality of life in the COVID-19 pandemic process in a Tunisian sample put forward that physical activity is related to the endangered quality of life in restrictions during the COVID-19 pandemic, and that the quality of life levels of individuals increase as their physical activity levels increase (Slimani et al., 2020).

It was emphasized that the necessary physical activity quantity for the positive effects on human health to be seen is for children and young people at least 3 sessions/60 minutes/moderate level per week, 150-300 minutes/moderate level or 75-150 minutes/highlevel activities for adults or activities of the same metabolic threshold level (Morphy \& Goodwin, 2012; Ministry of National Health, 2014) but it was also reported that $80 \%$ of world teenager population is not sufficiently physically active. Already low before the COVID-19 pandemic, physical activity levels decreased more due to the pandemic and restrictions related to the pandemic. In this regard, it is crucial that, including the restrictions, physical activity applications are adapted in different environments (home, office, etc.), and those measures are taken to continue the physical activity which has many benefits on human life. Physical education teachers are classified as professionals who can provide guidance and monitoring of these applications to be done in every walk of life correctly and safely as they were educated to achieve physical activity and healthy life skills (Avalos-Ramos et al., 2020; Cheung, 2020; McKenzie \& Lounsbery, 2013; Polet et al., 2019). Physical education teachers need to have knowledge and skill related to the physical activity, healthy and qualified life skills, and to 
make this knowledge and skill a lifestyle for the guidance and monitoring duty mentioned above to be done efficiently (Bradford et al., 2014). However, physical education teachers also got affected by changing lifestyles during the COVID-19 pandemic, individuals being indoors in an isolated way, and increased motionless time. Most of the studies done on physical education were directed to physical education lesson applications, and studies related to at what level the physical activity and quality of life levels of physical education teachers were affected were limited (Cruickshank et al., 2021; Lu et al., 2020; Mercier et al., 2021; Varea et al., 2020). In a study in Turkey, physical activity levels of physical education and sports teachers in the COVID-19 pandemic were examined, and it was reported that the physical activity level of physical education teachers decreased during the COVID-19 compared to before the pandemic (Erdogan et al., 2021). In another study in Mexico, physical activity levels of physical education teachers were compared before and during the COVID-19 pandemic (Hall-López, 2020). As a result of the study, it was seen that because teachers did not design different physical activity applications during the COVID-19 pandemic, their physical activity levels decreased by $69.8 \%$.

Studies on the relationship between physical activity and health-related quality of life reveal a positive finding when participation in physical activity, even at a minimal level, is compared to non-participation, and it has been emphasized that there may be gender differences regarding this issue (Qi et al., 2020; Slimani et al., 2020). In one of these studies, Morimoto et al. (2006) revealed the positive effect of physical activity on the quality of life of both women and men and stated that this effect was more extensive in women than in men. Contrary to these findings, Gouveia et al. (2019) in a study examining the quality of life and related variables, reported that men's quality of life was higher compared to women and that the positive relationship between quality of life and physical activity was observed only in men. The relationship between physical activity and quality of life has also been affected by COVID-19 restrictions, as in all areas of life (Antoun et al., 2021; Khan et al., 2021). Examining the relationship between physical activity and quality of life of male and female adults during the COVID-19 restrictions, Slimani et al. (2020) revealed that there is a positive relationship between physical activity and quality of life levels of both women and men and that as the level of physical activity increases, the level of quality of life also increases. In another study, the healthy living behaviors and quality of life of adult individuals during the COVID-19 restrictions were examined from a relational perspective, and as a result of the research, it was revealed that participation in physical activity is associated with the quality of life of both men and women and that the quality of life of individuals increases as the level of physical activity 
increases (Wang et al., 2020). These research findings show that the gender difference of the relationship between physical activity and quality of life during the COVID-19 pandemic has not been clarified and more research on the subject is needed.

In the light of the studies handled so far, it draws the attention that there are hardly any studies related to the physical activity and the quality of life of physical education teachers. In this regard, by thinking that it would contribute to the literature, this study aims to find out whether or not there is a relationship between physical activity during the COVID19 and the COVID-19 itself on the quality of life of female and male physical education teachers.

\section{METHODS}

Study Groups

A total of 155 physical education teachers, 71 women, and 84 men, working in Mersin in the 2021-2022 academic year made up the population of this population. While the average age of women teachers is 41.92 ( $\mathrm{SD} \pm 4.96)$, the average age of male teachers is 42.78 ( $\mathrm{SD} \pm 5.85)$.

\section{Data Collection Tools}

Personal Information Form, Godin-Shephard Leisure-Time Physical Activity Questionnaire (GSLTPAQ), and Effect of COVID-19 on Quality of Life Scale (COV19-QoLTR) were used in this study were data collection tools.

\section{Personal Information Form}

Prepared by researchers to identify the demographic characteristics of participant physical education teachers, there are questions related to gender (male, female) and age of participants in the Personal Information Form.

\section{Godin-Shephard Leisure-Time Physical Activity Questionnaire (GSLTPAQ)}

Developed by Godin and Shephard (1997) to put forward the physical activity levels of physical education teachers and adapted to Turkish culture by Yerlisu-Lapa and Yağar (2015), the first name of the questionnaire was Leisure-Time Exercise Questionnaire, and it was then published as Leisure-Time Physical Activity Questionnaire. While the questionnaire is a single factor, it is made up of a total of 3 questions, and the answers given to determine the leisure-time physical activity level as strenuous, moderate, and light. For calculating the total score, strenuous activities are multiplied by 9 , moderate by 5 , and light by 3 , and the scores are added. GSLTPAQ is formalized as follows:

$$
\text { GSLTPAQ score }=(9 \times \text { Strenuous })+(5 \times \text { Moderate })+(3 \times \text { Light })
$$


The total score obtained shows the individual's activity level within their leisure time. Evaluation ranges are as "active" for 24 points and higher, "moderately active" for 14-23 points, "insufficiently active/sedentary" for 13 points and lower.

\section{The COVID-19 Impact on Quality-of-life Scale (COV19-QoL}

In order to determine the effect of COVID-19 on the quality of life of physical education teachers, COV19-QoLtR, was developed by Repisti et al. (2020) and adapted to Turkish by Sümen and Adibelli (2021), was used in the study. COV19-QoLTR is a 5 point Likert scale and scaled as "totally agree $=5$, agree $=4$, neutral $=3$, disagree $=2$, totally disagree $=1$ ". The scale is single-dimensional and consists of 6 items. Items on the scale evaluate the feelings and ideas of the individuals within the last 7 days. The scale's total score is calculated by adding all points and dividing by the number of items on the scale. A higher score obtained from the scale shows that the COVID-19 pandemic has a significant effect on the quality of life of individuals. The reliability coefficient of the scale was calculated as .91. The calculated reliability coefficient in this study is .85 .

\section{Data Collection}

Necessary official permissions were taken from the Ministry of National Education before the data collection process began. To eliminate infection due to COVID-19, Personal Information Form, GSLTPAQ, and COV19-QoLTR were transferred to digital media through an application to prepare digital data collection tools. Data collection tools were sent to various digital communication applications (email, message, etc.) of the physical education teachers by informing them about the study and taking their approvals to participate in the study. The participants were reminded twice to increase returns in the data collection process.

\section{Data Analysis}

At the first step of data analysis, it was analyzed whether data showed a normal distribution, and it was found that it did not. Mann-Whitney U test was used to determine whether there is a statistically significant difference between GSLTPAQ and COV19-QoL ${ }_{T R}$ scores of participant female and male physical education teachers, and Spearman's Correlation Coefficient was used to determine whether there is a statistically significant relationship between GSLTPAQ and COV19-QoLTR.

\section{RESULTS}

The results of the Mann-Whitney U Test applied to determine whether there is a statistically significant relationship between the GSLTPAQ scores of participant male and 
female teachers showed that there is no statistically significant difference between the GSLTPAQ scores of female $(\bar{x}=39.75, S S=23.98)$ and male $(\bar{x}=41.64, S S=22.51)$ teachers $\mathrm{U}$ $=2722.00, \mathrm{p}=.35$ (Table 1). Additionally, the results of the Mann-Whitney U Test applied to determine whether there is a statistically significant difference between COV19-QoLTR scores of male and female physical education teachers also showed that there is no statistical difference between COV19-QoL ${ }_{\mathrm{TR}}$ scores of male and female teachers (Table 1).

Table 1. Descriptive Statistics of GSLTPAQ and COV19-QoL ${ }_{T R}$ Scores by Gender

\begin{tabular}{lcccccc}
\hline Gender & $n$ & $\bar{x}$ & SD & Med. & $U$ & $p$ \\
\hline GSLTPAQ score & & & & & & \\
Female & 71 & 39.75 & 23.98 & 33.00 & 2722.00 & .35 \\
Male & 84 & 41.64 & 22.51 & 37.00 & & \\
Total & 155 & 40.77 & 23.14 & 34.00 & & \\
COV19-QoL TR score & & & & & & \\
Female & 71 & 3.37 & .97 & 3.50 & 2713.50 & .33 \\
Male & 84 & 3.23 & .91 & 3.33 & & \\
$\quad$ Total & 155 & 3.29 & .94 & 3.33 & & \\
\hline
\end{tabular}

According to these findings, GSLTPAQ scores of female and male physical education teachers are similar and "active". In the research, it was revealed that $42.73 \%$ of 110 teachers in the "active" category were female, 52.27\% were male, and of 45 teachers in the "moderately active "category, 53.33\% were female and $46.67 \%$ male. It was observed that there was no physical education teacher in the "inactive" category among the participants. According to these findings, COV19-QOLTR scores of female and male physical education teachers are negative above average.

As GSLTPAQ and COV19-QoLtr scores of female and male teachers show similarity, Spearman's Correlation Coefficient analysis was applied to determine whether there is a statistically significant relationship between total scores obtained from GSLTPAQ and COV19QoL $_{\mathrm{TR}}$. The results obtained showed that there is a negatively significant but weak correlation between leisure-time physical activity of physical education teachers in the COVID-19 process and the level of effect of COVID-19 on the quality of their life $(r s=-.22, p<.01)$, and that the negative effect of COVID-19 on their quality of life decreases as leisure-time physical activity levels of teachers' increase. 


\section{DISCUSSION}

This research aims to study the relationship of leisure-time physical activity levels of physical education teachers in the COVID-19 process and the effect level of the COVID-19 on their quality of life, and it was found in pre-analysis that the physical activity levels of female and male physical education teachers and the effect level of the COVID-19 on the quality of life of teachers are similar. Results put forward that the physical activity level of female and male physical education teachers ranked in the "active" category, and that the COVID-19 affected the quality of life of teachers in a negative level above average. Besides, it was found that there is a significant but rather weak relationship between the physical activity levels of teachers and the level of effectiveness of the COVID-19 on quality of life and that the negative effect level of the COVID-19 on quality of life decreased as leisure-time physical activity levels of teachers increased.

In this study, although the leisure-time physical activity levels of male and female physical education teachers were similar and in the active category during the COVID-19 process, in many studies conducted in different countries, contrary to these research findings, there was a decrease in the level of physical activity mostly due to COVID-19 restrictions (Amini et al., 2021; Atakan et al., 2021; Dunton et al., 2020; Ghozy et al. 2021; Puccinelli et al., 2021; Rahman et al., 2020). Physical activity levels of adults in Spain aged 18-64 in the COVID19 process were studied, and it was reported that the physical activity level of especially young people, students, and those in highly active groups before the COVID-19 pandemic decreased (Castañeda-Babarro et al., 2020). Similarly, in Spain sampling, in a study examining the changes of adult individuals in participation in physical activity in early periods COVID-19 pandemic restrictions started, López-Bueno et al. (2020) stated a 20\% decrease in physical activity level in the first week of the restrictions. In the same study, it was identified that $60.6 \%$ of the participants were at a level to meet the physical activity suggestions of WHO before the COVID-19 restrictions, but the level of participants meeting these suggestions decreased to $48.9 \%$ in the restrictions process. In another study made in Spain sampling, it was stated that physical activity levels of individuals decreased significantly because of restrictions due to the COVID-19 pandemic again and that the rate of individuals doing physical activity for more than an hour decreased from $26.6 \%$ to $14.7 \%$ (Sánchez-Sánchez et al., 2020). Examining the effect of the COVID-19 pandemic and restrictions related to the pandemic on physical activity level through an application calculating daily step numbers worldwide, Tison et al. (2020) identified that although there are differences between the countries, the number of steps 
decreased $5.5 \%$ within the first 10 days after the announcement of the pandemic, and $27.3 \%$ within the first 30 days. Furthermore, in the study, it was identified that also in countries with low pandemic levels and so with more flexible about the restrictions, there is a decrease in the physical activity level defined with several steps. Again, by the data obtained from participants of different countries, Ammar et al. (2020) detected that due to the restrictions related to the COVID-19 pandemic, there was a decrease in the physical activity level of individuals at every level (advanced, medium, walking, etc.). Besides, it was identified in the same study that the daily sitting time of participants increased to 8 hours from 5 hours. It is thought that the main reasons for the decrease in participation in physical activities during the COVID-19 process that was put forward in studies in the literature are the unmatched global COVID-19 pandemic, restriction of daily activities of people with regard to country policies in order to prevent the infection of this disease and to provide people to keep in safety, and to make people spend most of (sometimes all of) their times at home, and keeping the participation to various social and movement activities (walking, running, cycling, dog walking, activities in sports fields, etc.) to a minimum level to keep the social distance (Giuntella et al., 2021; Haleem et al., 2020; Jadoo, 2020; McCarthy et al., 2021). It was seen that there are studies in literature examining the effect of the COVID-19 restrictions on physical activity levels of individuals from all walks of life, but that there is a limited number of studies focusing this point on physical education and sports field. In one of these limited studies that did not come across findings parallel to these research findings, Hall-López (2020) compared the physical activity level of physical education teachers before and during the COVID-19 pandemic in Mexico sampling and reported that the participation of physical education teachers in physical activities is $25.2 \%$ in a low level, $37.8 \%$ in medium and $37 \%$ in high level, but that in the restrictions process related to the COVID-19, the level of teachers doing physical activity in a low level increased by $49.8 \%$, but that those in a low level decreased by $25.5 \%$, and high level by $24.7 \%$. In another study reviewing the studies for the effect of the COVID19 pandemic on physical activity levels of university students, López-Valenciano et al. (2020) stated a decrease in physical activity levels of students with different levels (low, medium, and high level) depending on COVID-19 pandemic restrictions, but that students who do physical activities on a level suitable to the physical activity suggestions of WHO continued their physical activities in the same level during restrictions. Examining the effect of the quarantine process related to the COVID-19 pandemic on the physical activity level of individuals, Raiola et al. (2020) described that the physical activity level of athletes doing active sports was not affected by restrictions of the COVID-19 and that athletes got adapted to this process in a short 
time, that they continued physical activity in a home environment, but that they hope to turn back to before the COVID-19 pandemic process. These findings in the literature are in quality to support the results obtained towards physical education teachers who are in an expert and model position to all walks of life about physical activity, physical fitness, and healthy life (Cheung, 2020; Hall-López, 2020). It is thought that female and male physical education teachers' ranking in the "active" category in the COVID-19 pandemic process depends on their having knowledge and skills about the mentioned points and that they continue the physical activity by adapting this knowledge and skill according to the limited environment. When the findings of gender difference in participation in physical activity during the COVID-19 pandemic restrictions, which are also included in these research findings, are examined in comparison with the literature, it is striking that there are parallel and non-parallel research findings. In one of these studies, Orlandi et al. (2021) examined physical activity habits comparatively by gender during the COVID-19 restrictions. As a result of the research, it was stated that $56 \%$ of the participants in the study meet the WHO physical activity recommendations before the COVID-19 pandemic, but this rate was lower in women. In addition, it was stated that $52.1 \%$ of the female and male participants in the same study were sufficiently active during the COVID-19 restrictions, but this rate decreased in men. In another study, Castañeda-Babarro et al. (2020) stated that male and female participants participating in the research decreased in the duration of walking activity during the COVID-19 process, and the participation levels of male participants in vigorous physical activity decreased more than female participants. It has also been reported in the same study that sedentary time increased more in men than women, and accordingly, men reduced moderate physical activities by $8.8 \%$, but women increased these activities by $11 \%$. However, from these studies in the literature, which reveal contradictory findings, it is not clear how individuals from the field of physical education and sports are affected in terms of participation in physical activity during the COVID-19 process.

Turning into a global health crisis, the COVID-19 pandemic and restrictions taken as measures related to the pandemic affected the quality of life of individuals, together with physical activities stated in this study negatively in all the world (Bulguroğlu et al., 2021; Cihan \& Şahbaz Pirinççi, 2020; Epifanio et al., 2021; Guillasper et al., 2021; Ravens-Sieberer et al., 2021; Kasar \& Karaman, 2021). In a study with a large scope putting forward this negative effect, Al Dhaheri et al. (2021) studied the quality of life of individuals in the Middle East and Northern Africa in the process of restrictions in the COVID-19 and stated that the quality of life was influenced negatively in this process. Studying the quality of life of individuals in the 
quarantine process of the COVID-19 process in Portuguese sampling, Ferreira et al. (2021) reported that the quarantine process has a negative effect especially on the quality of life of women and old individuals. Examining the quality of life of individuals in Moroccan sampling following the $2^{\text {nd }}$ month of quarantine application of the COVID-19 pandemic, Samlani et al. (2020) found out that the quality of life of individuals is affected seriously negatively. In a study done in the Philippines with the participation of teachers, Rabacal et al. (2020) studied the effect of the COVID-19 on the quality of life and detected that it has a negative effect above average. Studying the quality of life of healthy adult individuals in Israel in an isolation process of the COVID-19 pandemic, Lipskaya-Velikovsky (2021) emphasized that the level of quality of life of all individuals, especially of women, young adults, and unemployed individuals, was affected negatively from this process and showed a decrease. The effect of the COVID-19 on the quality of life of individuals was examined in Africa, North America, Asia, Australia, Europe, and South Africa, and the negative effect of the COVID-19 on the quality of life of individuals was found as high in this study with a comprehensive scope, regardless of the area lived (Khodami et al., 2021). Similar to the findings of this study, studies both in Turkey and in other parts of the world put forward that the quality of life of individuals got affected negatively in the restrictions process of the COVID-19 pandemic. It is thought that the main reason for the COVID-19 pandemic in social, economic, and political areas all over the world (Ferreira et al., 2021; Melo-Oliveira et al., 2021; Mertens et al., 2020; Vitorino et al., 2021). In this study, although the level of quality of life of individuals in the COVID-19 process did not differ significantly according to gender, studies in the literature support and do not support this finding. In one of these studies, Ferreira et al. (2021) examined the quality of life of individuals during the COVID-19 process in terms of gender. They stated that the quality of life of women participating in the study during the COVID-19 quarantine was lower than men. In another study, Epifanio et al. (2021) examined the quality of life of individuals in the restrictions due to the COVID-19 pandemic. They revealed that female participants had a lower rate of life than men. These findings show that the difference in the quality of life due to COVID-19 restrictions by gender is not clear and prospective studies are needed.

Just like in this study, a negative relationship between the effect of the COVID-19 on physical activity and especially on the quality of life, in other words, that the level of quality of life increases as physical activity level increases, was put forward in different studies in the literature (Ciddi \& Yazgan, 2020; Tunç et al., 2020; Tural, 2020). In one of these studies, Ozdemir et al. (2020) examined the level of quality of life in the COVID-19 pandemic process and the effect of physical activity on the quality of life in Turkish sampling. They put forward 
as a result of the study that only $6.9 \%$ of participants are physically active, and that the level of quality of life increases as participation to the physical activity level in the COVID-19 pandemic process increases. Studying the difference between the level of quality of life of individuals exercising and not exercising in the COVID-19 pandemic process, Berk et al. (2021) put forward that the number of people not exercising before the pandemic increased to 513 from 133, that the number of people exercising 1-2 days weekly increased to 233 from 183, that the number of people exercising 3-4 days weekly decreased to 108 from 341, and that the number of those exercising 5-6 days weekly decreased to 53 from 250, and found that the level of quality of life of exercising participants higher compared to those not exercising. In another study examining physical activity level and quality of life in the COVID-19 pandemic process, Alzahrani et al. (2021) put forward that the level of quality of life of adult individuals feeling the medium and high-level negative effect of COVID-19 is at a lower level compared to the individuals feeling the negative effect of the COVID-19 in a low level. Additionally, in this study, no matter what the level (low, medium, high) is, the level of quality of life of individuals showing participation in physical activity is found higher compared to non-participants. Studying the physical activity and the level of quality of life of adult individuals in China in the restriction process of the COVID-19 pandemic, Wang et al. (2020) stated that the physical activity level of $52 \%$ of participants decreased in this process, that the sitting time of $67 \%$ and the lying/sleeping time of $61 \%$ increased, and reported that there is a significant relationship between physical activity level and quality of life, and that quality of life increases as physical activity level increases. Studies on the relationship between physical activity and the quality of life of women and men during the COVID-19 restrictions have also reached various results. For example, examining the relationship between physical activity and quality of life during the COVID-19 related restrictions, Slimani et al. (2020) showed that there is a positive correlation between physical activity and quality of life in both women and men, and that quality of life improves with increased physical activity. Another study investigated the healthy lifestyle and quality of life of adults under COVID-19 restrictions from a relationship perspective, and as a result of the study, participation in physical activity was associated with quality of life for both men and women and the quality of life of an individual increase with increasing physical activity (Wang et al., 2020). These findings derived from the literature also indicate that gender differences in the relationship between physical activity and quality of life in the COVID-19 restrictions are not clear, and further research is needed on this topic.

Several limitations need to be taken into account when interpreting the findings of this study. First, the analysis of the study was limited to the variables evaluated using the two data 
collection instruments (GSLTPAQ, COV19-QoL ${ }_{T R}$ ). In addition, the sample was relatively small and taken from a limited geographical area (Mersin) and it is unclear how the study findings will be applied to other regions.

\section{CONCLUSION}

As a result, female and male physical education teachers' physical activity levels are in the "active" category in the COVID-19 process, and the COVID-19 has a negative effect above average on the quality of life of female and male physical education teachers. Additionally, the negative impact of the COVID-19 on the quality of life decreases as the physical activity level of physical education teachers increases. Based on these results, future studies are suggested to be designed in a way to include teachers of other fields and allow interdisciplinary comparisons. Further studies are advised to be done to include different other variables that would possibly affect physical activity and the quality of life. It is advised that just as in physical education teachers, projects towards developing and popularizing various digital applications that would enable the society to do physical activity in a home environment by increasing the quality of life of individuals and information and hardware for physical activity that can be applied in different environments of society (house, gym, nature, stadium, swimming pool, etc.) are developed and actualized. In addition, an in-depth and comprehensive examination of the factors influencing physical education and sports teachers' physical activity levels during the COVID-19 restrictions in the "active" category with qualitative research methods is recommended for future research.

\section{Authors' contributions}

The first and the corresponding author designed the research. The first author collected the data and the corresponding author analyzed the data and interpreted the results. Both authors contributed equally to the introduction and discussion sections. The authors read and approved the final manuscript.

\section{Declaration of conflict interest}

The authors of this manuscript declare that there is no conflict of interest with any financial or non-financial organization regarding the subject matter or materials discussed in the manuscript. 


\section{REFERENCES}

Al Dhaheri, A. S., Bataineh, M. A. F., Mohamad, M. N., Ajab, A., Al Marzouqi, A., Jarrar, A. H., ... \& Cheikh Ismail, L. (2021). Impact of COVID-19 on mental health and quality of life: Is there any effect? A cross-sectional study of the MENA region. PloS One, 16(3), e0249107. doi.org/10.1371/journal.pone.0249107

Alfawaz, H., Yakout, S. M., Wani, K., Aljumah, G. A., Ansari, M. G., Khattak, M. N., ... \& AlDaghri, N. M. (2021). Dietary intake and mental health among Saudi adults during COVID-19 lockdown. International Journal of Environmental Research and Public Health, 18(4), 1653. doi.org/10.3390/ijerph18041653

Alzahrani, H., Alshehri, F., Alsufiany, M., Allam, H. H., Almeheyawi, R., Eid, M. M., \& Sadarangani, K. P. (2021). Impact of the 2019 coronavirus disease pandemic on healthrelated quality of life and psychological status: The role of physical activity. International Journal of Environmental Research and Public Health, 18(8), 3992. doi.org/10.3390/ijerph18083992

Amini, H., Habibi, S., Islamoglu, A. H., Isanejad, E., Uz, C., \& Daniyari, H. (2021). COVID-19 pandemic-induced physical inactivity: The necessity of updating the Global Action Plan on Physical Activity 2018-2030. Environmental Health and Preventive Medicine, 26(1), 1-3. doi.org/10.1186/s12199-021-00955-Z

Ammar, A., Brach, M., Trabelsi, K., Chtourou, H., Boukhris, O., Masmoudi, L., ... \& Hoekelmann, A. (2020). Effects of COVID-19 home confinement on eating behaviour and physical activity: Results of the ECLB-COVID19 International Online Survey. Nutrients, 12(6), 1583. doi.org/10.3390/nu12061583

Anokye, N. K., Trueman, P., Green, C., Pavey, T. G., \& Taylor, R. S. (2012). Physical activity and health related quality of life. BMC Public Health, 12(1), 1-8. doi.org/10.1186/1471$\underline{2458-12-624}$

Antoun, J., Brown, D. J., Jones, D. J., Sangala, N. C., Lewis, R. J., Shepherd, A. I., ... \& Saynor, Z. L. (2021). Understanding the impact of initial COVID-19 restrictions on physical activity, wellbeing, and quality of life in shielding adults with end-stage renal disease in the United Kingdom dialysing at home versus in-centre and their experiences with telemedicine. International Journal of Environmental Research and Public Health, 18(6), 3144. doi.org/10.3390/ijerph18063144

Atakan, M. M., Aktitiz, S., \& Kayhan, M. (2021). COVID-19 versus physical inactivity-a selfreported questionnaire study. Turkish Journal of Sports Medicine, 56(2), 67-72. doi.org/10.47447/tjsm.0506

Avalos-Ramos, M. A., Ruiz, M. Á. M., \& Merma-Molina, G. (2020). The image of physical education teachers held by students from two universities. Journal of Physical Education, 31, e3141. doi.org/10.4025/jphyseduc.v31i1.3141

Bas, D., Martin, M., Pollack, C., \& Venne, R. (2020). The impact of COVID-19 on sport, physical activity, and well-being and its effects on social development. United Nations Department of Economic and Social Affairs. Retrieved on January 8, 2021, from https://www.un.org/development/desa/dspd/wpcontent/uploads/sites/22/2020 L05/PB_73.Pdf

Berk, Y., Öner, S., \& Sarıkaya, M. (2021). Investigation of the effect of physical activity on the quality of life and mood during COVID-19 pandemia process. Journal of ROL Sports Science, 2(2), 52-64. doi.org/10.29228/ roljournal.49619 
Bize, R., Johnson, J. A., \& Plotnikoff, R. C. (2007). Physical activity level and health-related quality of life in the general adult population: A systematic review. Preventive Medicine, 45(6), 401-415. doi.org/10.1016/j.ypmed.2007.07.017

Bradford, B. D., Hickson, C. N., \& Evaniew, A. K. (2014). Role modeling: The forgotten part of elementary school physical education. Journal of Higher Education Theory and Practice, 14(5), 18-23.

Bulguroğlu, H. İ., Bulguroğlu, M., \& Özaslan, A. (2021). Investigation of physical activity, quality of life, and depression levels of university students during the Covid-19 pandemic process. Acibadem University Health Sciences Journal, 12(2), 306-311. doi.org/10.31067/acusaglik.852175

Caputo, E. L., \& Reichert, F. F. (2020). Studies of physical activity and COVID-19 during the pandemic: A scoping review. Journal of Physical Activity and Health, 17(12), 1275-1284. doi.org/10.1123/jpah.2020-0406

Castañeda-Babarro, A., Arbillaga-Etxarri, A., Gutiérrez-Santamaría, B., \& Coca, A. (2020). Physical activity change during COVID-19 confinement. International Journal of Environmental Research and Public Health, 17(18), 6878. doi.org/10.3390/ijerph17186878

Cheung, P. (2020). Teachers as role models for physical activity: Are preschool children more active when their teachers are active?. European Physical Education Review, 26(1), 101110. doi.org/10.1177/1356336X19835240

Ciddi, K. P., \& Yazgan, E. (2020). The effect of physical activity status on quality of life during social isolation in Covid-19 epidemic. İstanbul Ticaret Üniversitesi Sosyal Bilimler Dergisi, Covid-19 Sosyal Bilimler Özel Sayısi, 262-279. https://dergipark.org.tr/tr/pub/iticusbe/issue/55168/754235

Cihan, E., \& Şahbaz Pirinççi, C. (2020). Life quality relationship of young population with physical activity level and depression level in COVID19 pandemic period. Selçuk Sağhlk Dergisi, 1(COVID-19 Ozel say1), https://dergipark.org.tr/tr/pub/ssd/issue/57170/761644

Cruickshank, V., Pill, S., \& Mainsbridge, C. (2021). 'Just do some physical activity': Exploring experiences of teaching physical education online during Covid-19. Issues in Educational Research, 31(1), 76-93. http://www.iier.org.au/iier31/cruickshank$\underline{\text { abs.html }}$

Dunton, G. F., Wang, S. D., Do, B., \& Courtney, J. (2020). Early effects of the COVID-19 pandemic on physical activity locations and behaviors in adults living in the United States. Preventive Medicine Reports, 20, 101241. doi.org/10.1016/j.pmedr.2020.101241

Epifanio, M. S., Andrei, F., Mancini, G., Agostini, F., Piombo, M. A., Spicuzza, V., ... \& La Grutta, S. (2021). The impact of COVID-19 pandemic and lockdown measures on quality of life among Italian general population. Journal of Clinical Medicine, 10(2), 289. doi.org/10.3390/jcm10020289

Erdogan, R., Yilmaz, M., \& Aydemir, I. (2021). Determination of physical education and sports teachers' nutrition habits and physical activity levels in the global epidemic (COVID19) process. Asian Journal of Education and Training, 7(1), 51-59. doi.org/10.20448/journal.522.2021.71.51.59

Ferreira, L. N., Pereira, L. N., da Fé Brás, M., \& Ilchuk, K. (2021). Quality of life under the COVID-19 quarantine. Quality of Life Research, 30(5), 1389-1405. doi.org/10.1007/s11136-020-02724-x 
Fraenkel, J. R., Wallen, N. E., Hyun, H. H. (2011). How to Design and Evaluate Research in Education (Eighth Edit). United State of America: Mc Graw Hill Companies, Inc.

Ghozy, S., Abdelaal, A., Shah, J., Parker, K. E., \& Islam, S. M. S. (2021). COVID-19 and physical inactivity: Teetering on the edge of a deadlier pandemic?. Journal of Global Health, 11, 13. doi.org/10.7189/jogh.11.03031

Gill, D. L., Hammond, C. C., Reifsteck, E. J., Jehu, C. M., Williams, R. A., Adams, M. M., ... \& Shang, Y. T. (2013). Physical activity and quality of life. Journal of Preventive Medicine and Public Health, 46(Suppl 1), S28. doi.org/10.3961/jpmph.2013.46.S.S28

Giuntella, O., Hyde, K., Saccardo, S., \& Sadoff, S. (2021). Lifestyle and mental health disruptions during COVID-19. Proceedings of the National Academy of Sciences, 118(9), e2016632118. doi.org/10.1073/pnas.2016632118

Godin, G., \& Shephard, R.J. (1997). Godin leisure-time exercise questionnaire. Medicine and Science in Sports and Exercise, 29(Supplement), 36-38.

Gouveia, B. R., Ihle, A., Kliegel, M., Freitas, D. L., \& Gouveia, É. R. (2019). Sex differences in relation patterns between health-related quality of life of older adults and its correlates: A population-based cross-sectional study in Madeira, Portugal. Primary Health Care Research E Development, 20(e54), 1-5. doi.org/10.1017/S1463423618000233

Guillasper, J., Oducado, R. M., \& Soriano, G. (2021). Protective role of resilience on COVID-19 impact on the quality of life of nursing students in the Philippines. Belitung Nursing Journal, 7(1), 43-49. doi.org/10.33546/bnj.1297

Haleem, A., Javaid, M., \& Vaishya, R. (2020). Effects of COVID-19 pandemic in daily life. Current Medicine Research and Practice, 10(2), 78-79. doi.org/10.1016/j.cmrp.2020.03.011

Hall-López, J. A. (2020). Physical activity levels in physical education teachers before and during school suspension brought by the COVID-19 quarantine. Facta Universitatis, Series: Physical Education and Sport, 18(2), 475-481. doi.org/10.22190/FUPES200607045H

Jadoo, S. A. A. (2020). COVID-19 pandemic is a worldwide typical biopsychosocial crisis. Journal of Ideas in Health, 3(2), 152-154. https:/ / doi.org/10.47108/jidhealth.Vol3.Iss2.58

Kalaycı, M., Güleroğlu, F., Gönültaş, B., \& Kalaycı, M. C. (2021). The importance of physical activity and exercise in Covid-19 pandemic. GERMENICA The Journal of Physical Education and Sports Science, 2(1), 31-40. https://dergipark.org.tr/tr/pub/germenica/issue/61307/914853

Kasar, K. S., \& Karaman, E. (2021). Life in lockdown: Social isolation, loneliness and quality of life in the elderly during the COVID-19 pandemic: A scoping review. Geriatric Nursing, S0197, 4572. doi.org/10.1016/j.gerinurse.2021.03.010

Khan, A. G., Kamruzzaman, M., Rahman, M. N., Mahmood, M., \& Uddin, M. A. (2021). Quality of life in the COVID-19 outbreak: Influence of psychological distress, government strategies, social distancing, and emotional recovery. Heliyon, 7(3), e06407. doi.org/10.1016/j.heliyon.2021.e06407

Khodami, M. A., Seif, M. H., Koochakzadeh, R. S., Fathi, R., \& Kaur, H. (2021, February). Perceived stress, emotion regulation and quality of life during the Covid-19 outbreak: A multi-cultural online survey. Annales Médico-Psychologiques, 3044, 1-5. doi.org/10.1016/j.amp.2021.02.005 
Lipskaya-Velikovsky, L. (2021). COVID-19 isolation in healthy population in Israel: Challenges in daily life, mental health, resilience, and quality of life. International Journal of Environmental Research and Public Health, 18(3), 999. doi.org/10.3390/ijerph18030999

López-Bueno, R., Calatayud, J., Andersen, L. L., Balsalobre-Fernández, C., Casaña, J., Casajús, J. A., ... \& López-Sánchez, G. F. (2020). Immediate impact of the COVID-19 confinement on physical activity levels in Spanish adults. Sustainability, 12(14), 5708. doi.org/10.3390/su12145708

López-Valenciano, A., Suárez-Iglesias, D., Sanchez-Lastra, M. A., \& Ayán, C. (2020). Impact of COVID-19 pandemic on university students' physical activity levels: An early systematic review. Frontiers in Psychology, 11, 624567. doi.org/10.3389/fpsyg.2020.624567

Lu, C., Barrett, J., \& Lu, O. (2020). Teaching Physical Education Teacher Education (PETE) online: Challenges and solutions. Brock Education: A Journal of Educational Research and Practice, 29(2), 13-17. doi.org/10.26522/brocked.v29I2.828

Marquez, D. X., Aguiñaga, S., Vásquez, P. M., Conroy, D. E., Erickson, K. I., Hillman, C., ... \& Powell, K. E. (2020). A systematic review of physical activity and quality of life and well-being. Translational Behavioral Medicine, 10(5), 1098-1109. doi.org/10.1093/tbm/ibz198

McCarthy, H., Potts, H. W., \& Fisher, A. (2021). Physical activity behavior before, during, and after COVID-19 restrictions: Longitudinal Smartphone-Tracking Study of adults in the United Kingdom. Journal of Medical Internet Research, 23(2), e23701. doi.org/10.2196/23701

McKenzie, T. L., \& Lounsbery, M. A. (2013). Physical education teacher effectiveness in a public health context. Research Quarterly for Exercise and Sport, 84(4), 419-430. doi.org/10.1080/02701367.2013.844025

Melo-Oliveira, M. E., Sá-Caputo, D., Bachur, J. A., Paineiras-Domingos, L. L., Sonza, A., Lacerda, A. C., ... \& Bernardo-Filho, M. (2021). Reported quality of life in countries with cases of COVID19: A systematic review. Expert Review of Respiratory Medicine, 15(2), 213-220. doi.org/10.1080/17476348.2021.1826315

Mercier, K., Centeio, E., Garn, A., Erwin, H., Marttinen, R., \& Foley, J. (2021). Physical education teachers' experiences with remote instruction during the initial phase of the COVID-19 pandemic. Journal of Teaching in Physical Education, 40(2), 337-342. doi.org/10.1123/jtpe.2020-0272

Mertens, G., Gerritsen, L., Duijndam, S., Salemink, E., \& Engelhard, I. (2020). Fear of the coronavirus (COVID-19): Predictors in an online study conducted in March 2020. Journal of Anxiety Disorders, 74, 102258. doi.org/10.1016/j.janxdis.2020.102258

Meyer, J., McDowell, C., Lansing, J., Brower, C., Smith, L., Tully, M., \& Herring, M. (2020). Changes in physical activity and sedentary behavior in response to COVID-19 and their associations with mental health in 3052 US adults. International Journal of Environmental Research and Public Health, 17(18), 6469. doi.org/10.3390/ijerph17186469

Ministry of National Health (2014). Turkish Physical Activity Guide [Türkiye Fiziksel Aktivite Rehberi]. Ministry of National Health, General Directorate of Public Health. Obezite, Diyabet ve Metabolik Hastalıklar Daire Başkanlığı. Retrieved from 
https://hsgm.saglik.gov.tr/depo/birimler/saglikli-beslenme-hareketli-hayat$\underline{\mathrm{db} / \text { Fiziksel_Aktivite_Rehberi/Turkiye_Fiziksel_Aktivite_Rehberi.pdf }}$

Morimoto, T., Oguma, Y., Yamazaki, S., Sokejima, S., Nakayama, T., \& Fukuhara, S. (2006). Gender differences in effects of physical activity on quality of life and resource utilization. Quality of Life Research, 15(3), 537-546. doi.org/10.1007/s11136-005-3033-2

Morphy, L. Y., \& Goodwin, D. L. (2012). The experience of choice in physical activity contexts for adults with mobility impairments. Adapted Physical Activity Quarterly, 29(2), 132150. doi.org/10.1123/apaq.29.2.132

Orlandi, M., Rosselli, M., Pellegrino, A., Boddi, M., Stefani, L., Toncelli, L., \& Modesti, P. A. (2021). Gender differences in the impact on physical activity and lifestyle in Italy during the lockdown, due to the COVID-19 pandemic. Nutrition, Metabolism and Cardiovascular Diseases, 31(7), 2173-2180. doi.org/10.1016/j.numecd.2021.03.011

Ozdemir, F., Cansel, N., Kizilay, F., Guldogan, E., Ucuz, I., Sinanoglu, B., ... \& Cumurcu, H. B. (2020). The role of physical activity on mental health and quality of life during COVID19 outbreak: A cross-sectional study. European Journal of Integrative Medicine, 40, 101248. doi.org/10.1016/j.eujim.2020.101248

Polet, J., Hassandra, M., Lintunen, T., Laukkanen, A., Hankonen, N., Hirvensalo, M., ... \& Hagger, M. S. (2019). Using physical education to promote out-of-school physical activity in lower secondary school students-A randomized controlled trial protocol. BMC Public Health, 19(1), 1-15. doi.org/10.1186/s12889-019-6478-x

Pucci, G. C. M. F., Rech, C. R., Fermino, R. C., \& Reis, R. S. (2012). Association between physical activity and quality of life in adults. Revista de Saúde Pública, 46, 166-179. doi.org/10.1590/S0034-89102012000100021

Puccinelli, P. J., da Costa, T. S., Seffrin, A., de Lira, C. A. B., Vancini, R. L., Nikolaidis, P. T., ... \& Andrade, M. S. (2021). Reduced level of physical activity during COVID-19 pandemic is associated with depression and anxiety levels: An internet-based survey. BMC Public Health, 21(1), 1-11. doi.org/10.1186/s12889-021-10470-z

Qi, M., Li, P., Moyle, W., Weeks, B., \& Jones, C. (2020). Physical activity, health-related quality of life, and stress among the Chinese adult population during the COVID-19 pandemic. International Journal of Environmental Research and Public Health, 17(18), 6494. doi.org/10.3390/ijerph17186494

Rabacal, J., Oducado, R. M., \& Tamdang, K. (2020). COVID-19 impact on the quality of life of teachers: A cross-sectional study. Asian Journal for Public Opinion Research, 8(4), 478-492. doi.org/10.15206/ajpor.2020.8.4.478

Rahman, M. E., Islam, M. S., Bishwas, M. S., Moonajilin, M. S., \& Gozal, D. (2020). Physical inactivity and sedentary behaviors in the Bangladeshi population during the COVID19 pandemic: An online cross-sectional survey. Heliyon, 6(10), e05392. doi.org/10.1016/j.heliyon.2020.e05392

Raiola, G., Aliberti, S., Esposito, G., Altavilla, G., D'Isanto, T., \& D'Elia, F. (2020). How has the practice of physical activity changed during the covid-19 quarantine? A preliminary survey. Teoriâ ta Metodika Fizičnogo Vihovannâ, 20(4), 242-247. doi.org/10.17309/tmfv.2020.4.07

Ravens-Sieberer, U., Kaman, A., Erhart, M., Devine, J., Schlack, R., \& Otto, C. (2021). Impact of the COVID-19 pandemic on quality of life and mental health in children and 
adolescents in Germany. European Child \& Adolescent Psychiatry, Ahead of Print, 1-11. doi.org/10.1007/s00787-021-01726-5

Repišti, S., Jovanović, N., Kuzman, M. R., Medved, S., Jerotić, S., Ribić, E., ... \& Russo, M. (2020). How to measure the impact of the COVID-19 pandemic on quality of life: COV19-QoLthe development, reliability, and validity of a new scale. Global Psychiatry, 3(2), 201-210. doi.org/10.2478/gp-2020-0016

Samlani, Z., Lemfadli, Y., Errami, A. A., Oubaha, S., \& Krati, K. (2020). The impact of the COVID-19 pandemic on quality of life and well-being in Morocco. Archives of Community Medicine and Public Health, 6(2), 130-134. doi.org/10.20944/preprints202006.0287.v1

Slimani, M., Paravlic, A., Mbarek, F., Bragazzi, N. L., \& Tod, D. (2020). The relationship between physical activity and quality of life during the confinement induced by COVID-19 outbreak: A pilot study in Tunisia. Frontiers in Psychology, 11, 1882. doi.org/10.3389/fpsyg.2020.01882

Sümen, A., \& Adibelli, D. (2021). Adaptation of the COV19-QoL Scale to Turkish culture: Its psychometric properties in diagnosed and undiagnosed individuals. Death Studies, Ahead of Print, 1-8. doi.org/10.1080/07481187.2021.1925376

Sánchez-Sánchez, E., Ramírez-Vargas, G., Avellaneda-López, Y., Orellana-Pecino, J. I., GarcíaMarín, E., \& Díaz-Jimenez, J. (2020). Eating habits and physical activity of the Spanish population during the COVID-19 pandemic period. Nutrients, 12(9), 2826. doi.org/10.3390/nu12092826

Stockwell, S., Trott, M., Tully, M., Shin, J., Barnett, Y., Butler, L., ... \& Smith, L. (2021). Changes in physical activity and sedentary behaviours from before to during the COVID-19 pandemic lockdown: A systematic review. BMJ Open Sport E Exercise Medicine, 7(1), e000960. doi.org/10.1136/bmjsem-2020-000960

Theis, N., Campbell, N., De Leeuw, J., Owen, M., Schenke, K. C. (2021). The effects of COVID19 restrictions on physical activity and mental health of children and young adults with physical and/or intellectual disabilities. Disability and Health Journal, 14(3), 101064. doi.org/10.1016/j.dhjo.2021.101064

Tison, G. H., Avram, R., Kuhar, P., Abreau, S., Marcus, G. M., Pletcher, M. J., \& Olgin, J. E. (2020). Worldwide effect of COVID-19 on physical activity: A descriptive study. Annals of Internal Medicine, 173(9), 767-770. doi.org/10.7326/M20-2665

Tural, E. (2020). The effect of physical activity level on the quality of life in COVID-19 pandemic period home quarantine. Van Health Sciences Journal, 13(Special Issue), 18-26. https://dergipark.org.tr/tr/pub/vansaglik/issue/56982/738909

Tunç, A. Ç., Zorba, E., ve Çingöz, Y. E. (2020). The effect of exercise on quality of life in the period of pandemic (Covid 19). International Journal of Contemporary Educational Studies, 6(1), 127-135. https://dergipark.org.tr/tr/pub/intjces/issue/55238/749857

Varea, V., González-Calvo, G., \& García-Monge, A. (2020). Exploring the changes of physical education in the age of Covid-19. Physical Education and Sport Pedagogy, Ahead of Print, 1-11. doi.org/10.1080/17408989.2020.1861233

Vagetti, G. C., Barbosa, V. C., Moreira, N. B., Oliveira, V. D., Mazzardo, O., \& Campos, W. D. (2014). Association between physical activity and quality of life in the elderly: A systematic review, 2000-2012. Brazilian Journal of Psychiatry, 36, 76-88. doi.org/10.1590/1516-4446-2012-0895 
Vitorino, L. M., Júnior, G. H. Y., Gonzaga, G., Dias, I. F., Pereira, J. P. L., Ribeiro, I. M. G., ... \& Trzesniak, C. (2021). Factors associated with mental health and quality of life during the COVID-19 pandemic in Brazil. BJPsych Open, 7(3), E103. doi.org/10.1192/bjo.2021.62

Wang, X., Lei, S. M., Le, S., Yang, Y., Zhang, B., Yao, W., ... \& Cheng, S. (2020). Bidirectional influence of the COVID-19 pandemic lockdowns on health behaviors and quality of life among Chinese adults. International Journal of Environmental Research and Public Health, 17(15), 5575. doi.org/10.3390/ijerph17155575

World Health Organization [WHO] (2020). WHO guidelines on physical activity and sedentary behaviour. Geneva: World Health Organization; 2020. License: CC BY-NC$\begin{array}{lllll}\text { SA } & 3.0 & \text { IGO. } & \text { Retrieved }\end{array}$ https://apps.who.int/iris/bitstream/handle/10665/337001/9789240014886-eng.pdf

World Health Organization (2021). High rates of childhood obesity alarming given anticipated impact of COVID-19 pandemic. World Health Organization Regional Office for Europe. Retrieved from https://www.euro.who.int/en/mediacentre/sections/press-releases/2021/high-rates-of-childhood-obesity-alarminggiven-anticipated-impact-of-COVID-19-pandemic

Yerlisu-Lapa, T., \& Yağar, G. (2015, 28-30 May). Validity and reliability study of leisure time exercise questionnaire into Turkish [Oral Presentation]. 2nd international Sports Science, Tourism and Recreation Student Congress, Afyon Kocatepe University, Afyon.

Yıldırım, M., Akyol, A., \& Ersoy, G. (2008). Şişmanlık (Obezite) ve Fiziksel Aktivite, Enerji Dengesinin Aktivite Yönüne Bir Bakış. Klasmat Yayınevi, Ankara. 